\title{
Prevalence of Common Mental Disorders and Factors Associated with These Disorders among Pregnant Women Attend Ante Natal Care Services at Hawassa Referral Hospital, Ethiopia, 2016
}

Yacob Abraham ${ }^{1 *}$, Zewede Olitaye ${ }^{2}$, Tamiyalew Alemie ${ }^{3}$, Bereket Tsegaye ${ }^{3}$ and Eniyew Andualem ${ }^{3}$

${ }^{1}$ Department of Psychiatry, Hawasa University College of Medicine and Health Science, Hawasa, Ethiopia

${ }^{2}$ Department of Nursing, Hawasa University College of Medicine and Health Science, Hawasa, Ethiopia

${ }^{3}$ Compressive Specialized Hospital, Hawassa University, Awassa, Ethiopia

\begin{abstract}
Background: Common mental disorder such as depression, somatoform disorder and anxiety are increasingly recognized for their burden in low resource countries such as Ethiopia. However, the magnitude of antenatal common mental disorder in Ethiopia is not well established. Pregnancy is generally assumed to be a happy time, both for parents and society as a whole. But pregnancy can be a difficult and even a dangerous period for women living in low and middle income countries.

Objective: To assess the prevalence of common mental disorders and identify factors associated with these disorders among pregnant women attend ante natal care services at Hawassa referral hospital, Ethiopia, 2016.

Methodology: A cross-sectional study was employed among 232 pregnant women, from April 01-May 15. Systematic sampling technique was employed to select the study population. The self-reporting questionnaires (SRQ20) were used to detect common mental disorders. Statistical Package of Social Science (SPSS) version 20 was used in the statistical analysis.

Results: The prevalence of common mental disorder was high. Poor health status before pregnancy like, minor health problems (headache) (AOR, $95 \% \mathrm{Cl} 2(1.06-3.77$ ), ongoing health concern (diabetes mellitus) (AOR, $95 \% \mathrm{Cl}$ 2.83(1.21-6.66), and serious health problem like hypertension (AOR, 95\% Cl 4.17(1.24-13.98) were all independently associated with common mental disorder among pregnant women.

Conclusion: The prevalence of common mental disorder among pregnant women who attended antenatal care follow up at HURH was higher and previous history of health problem before current pregnancy was significantly associated with common mental disorder. Therefore health care providers responsible for ANC must be trained about the relevance and detection of CMD during pregnancy and proper counseling and emotional support should be given for women exhibiting the risk factors.
\end{abstract}

Keywords: Antenatal care; Common mental disorders; Pregnancy

Abbreviations: AOR: Adjusted Odds Ratio; IRB: Institutional Review Board CMDs: Common Mental Disorders; SNNP: Southern Nation Nationality and People of Ethiopia; SRQ: Self-reporting Questionnaire; SPSS: Statistical Package For social Sciences; ART: Antiretroviral Therapy

\section{Introduction}

According to the World Health Organization (WHO) health is not the mere absence of disease but a complete physical, mental, social, emotional and spiritual well-being [1]. Mental health refers to a broad array of activities directly or indirectly related to the mental well-being component included in the WHO definition of mental health. "A being of well-being, in which the individuals realizes his or her own abilities, can cope with the normal stresses of life, can work productively and fruitfully and is able to make a contribution to his or her community [2]. Mental disorders is a collection of mental problems that may not fall into standard diagnostic criteria and are characterized by symptoms of insomnia, fatigue, irritability, forgetfulness difficulty in concentrating, and somatic complaints [3].

Common Mental Disorder (CMD) is a mental health problem which manifest with different levels depressive, anxiety, panic or somatic symptoms. It also presents without actually being ill in a medical sense. This problems has a direct or indirect effects on the individual's psychology, social functioning and affects many aspects of life including relationships, work and health [4].
Pregnancy is a time when a woman experiences major psychological and biological changes. Many factors can affect the emotional state of the mother during pregnancy. These changes might predispose her for mental distress. Studies have shown grave consequences both on the mother and on the fetus in high and LMIC countries like Ethiopia. Screening might decrease the occurrence, early treatment and prevention of complications of CMD [5].

A qualitative study in rural Butajira, south central Ethiopia, found that emotional distress in pregnancy was linked to fear of dying in childbirth, becoming pregnant within one year of delivery of the previous child, marital and economic difficulties and unwanted pregnancy, for example when a child is conceived outside of marriage. In a context where women may be held responsible for poor prenatal outcomes, prenatal depression may also be expected to be more common [6].

*Corresponding author: Yacob Abraham, Department of Psychiatry, Hawasa University College of Medicine and Health Science, Hawasa, Ethiopia, Tel: +251916-58-06-32; E-mail: yacobabraham12@gmail.com

Received May 11, 2017; Accepted July 28, 2017; Published August 02, 2017

Citation: Abraham Y, Olitaye Z, Alemie T, Tsegaye B, Andualem E (2017) Prevalence of Common Mental Disorders and Factors Associated with These Disorders among Pregnant Women Attend Ante Natal Care Services at Hawassa Referral Hospital, Ethiopia, 2016. J Health Med Informat 8: 280. doi: 10.4172/2157-7420.1000280

Copyright: () 2017 Abraham Y, et al. This is an open-access article distributed under the terms of the Creative Commons Attribution License, which permits unrestricted use, distribution, and reproduction in any medium, provided the original author and source are credited. 
Citation: Abraham Y, Olitaye Z, Alemie T, Tsegaye B, Andualem E (2017) Prevalence of Common Mental Disorders and Factors Associated with These Disorders among Pregnant Women Attend Ante Natal Care Services at Hawassa Referral Hospital, Ethiopia, 2016. J Health Med Informat 8: 280. doi: 10.4172/2157-7420.1000280

Page 2 of 7

Even though there is evidence that socio-cultural practices may help to maintain prenatal mental health in women in rural Ethiopia, this might not be the case in urban settings where prenatal rituals are not practiced strongly. The lack of awareness about depression in pregnancy and stigma in reporting depression during pregnancy means that the majority of women with prenatal depression in Ethiopia remain untreated, with adverse consequences for both themselves and their babies [6]

For all of the reasons summarized above, there is a strong argument to try to address the large gap in untreated prenatal depression. The prenatal period is the time in a woman's life when she is most likely to be in contact with health services through attendance at Antenatal Care Clinics (ANC). In Addis Ababa, around 90\% of pregnant women attend ANC [7].

Significant proportion of the world population is affected by common mental disorder of which pregnant women are the once. Studies have revealed pregnancy has been shown to increase women's vulnerability to mental disorders in different countries like Bangladesh and Pakistan had experienced depression and anxiety. There was a consensus among studies that the mean prevalence of CMD during pregnancy is $20 \%$ [8].

In a prospective cohort study carried out in Brazil, the prevalence of prenatal Common mental disorder (CMD) was 33.6\%, with $7.6 \%$ of newborns having Low Birth Weight (LBW) and 6.9\% pre-term births, but the study did not find any association between CMD or LBW or preterm delivery. The study concluded that CMD prevalence is high among low-income and low risk pregnant women attending a public health service [9]. In population-based cohort studies from Bangladesh [10] and Pakistan [11] and a facility-based. Cohort study from India [12], prenatal depressive and anxiety symptoms were associated significantly with LBW. In a study done in rural South Africa, where there is a high prevalence of HIV and where most women will test for HIV for the first time during their pregnancy, findings were of a high prevalence of depression (46.7\%). Lack of access to a regular income and never having practical support from a partner, partnership and family conflict, as well as testing HIV positive were significantly associated with depression [13].

Pregnancy is generally assumed to be a happy time, both for parents and for society as a whole, but pregnancy can be a difficult and even a dangerous period for women living in low- and Middle-income countries (lmics). In Ethiopia, according to the 2013 global report by the World Health Organization (WHO), maternal mortality is estimated to be $420 / 100,000$ live births [14].

In this harsh reproductive health context, it is perhaps not surprising that the prevalence of Common mental disorders during the antenatal period, mostly depression and anxiety (15.6\%), is found to be higher in pregnant women in lmics compared to women living in high-income Countries [15]. In developing countries common mental disorders are not regarded as life threatening problems. Seems too insignificant, unworthy and lacking public health attention. Because in these countries morbidity and mortality due to malnutrition and infectious diseases are very common [2].

In order to guide development of appropriate interventions, it is critical to understand the extent to which pregnant women are prone to CMD. Therefore interventions are required that address both the social and medical risk of CMD and the disabilities and economic deprivation that are a consequence of CMD.

\section{Materials and Methods}

\section{Study setting and population}

Institutional based cross sectional study was carried from April 01 to May 15, 2016 in Hawassa University referral Hospital. Pregnant women attending Antenatal care in the Hospital during study period were included in the study.

The final sample size was 215 and systematic sampling technique was employed to select the study population based on willingness and conditions of inclusion and exclusion criteria.

\section{Variables}

Dependent variables

- Common mental disorder: Yes or No.

Independent variables

A. Demographic variable

- Age;

- Marital status;

- Ethnicity;

- Religion;

- Educational level.

B. Socioeconomic status

- Low income/household income

C. History of substance use

- Khat;

- Tobacco (cigarette);

- Alcohol.

D. Obstetric variables

- Miscarriages;

- Abortions;

- Gestational age.

E. Current pregnancy variables

- Unplanned pregnancy;

- Unwanted pregnancy.

F. History of chronic illness

- DM;

- STIS/including HIV;

- Hypertension.

G. Psychological factors

- Community support

- Baby's father support;

- Marital. 
Citation: Abraham Y, Olitaye Z, Alemie T, Tsegaye B, Andualem E (2017) Prevalence of Common Mental Disorders and Factors Associated with These Disorders among Pregnant Women Attend Ante Natal Care Services at Hawassa Referral Hospital, Ethiopia, 2016. J Health Med Informat 8: 280. doi: 10.4172/2157-7420.1000280

Page 3 of 7

\section{Data collection and analysis}

Data collection tool: Structured interview questionnaire and measurement scales prepared in English and Amharic languages and used for data collection. The data questionnaire consists of two main parts:

- Questionnaires on Demographic characteristics, socioeconomic status and history of substance use, obstetric variables, current pregnancy variables, history of chronic illness, psychological factors.

- $\quad$ Self-Reporting Questionnaire (SRQ).

SQR: In order measure the presence of mental illness our study employed the self-reporting questionnaires 20 item (SRQ-20). This consists of 20 yes/no questions with a reference period of the previous thirty days. It had acceptable level of reliability and validity in developing countries and is recommended by the world health organization (WHO) as a screening tool. It has previously been used to measure maternal illness in a four country study which included in Ethiopia where a cut off score of 6 or more was used to separate probable non-cases/cased of conmen mental disorder [16].

Data collection: First, prepared the hard copy of those questionnaires then select among the five members of the group, who are final year regular nursing students of Hawassa University to disseminate the questionnaire by attending at the area before conducted the main study.

The study participants were informed by the data collectors about their voluntary participation, purpose of the study with its importance as well as the significance of true information provision, and confidentiality issues. During data collection the data collectors provided counseling for emotional support and appropriate information to avoid miss- conception in mental health issues.

\section{Data quality control measures}

To assure the data quality, the questionnaire was translated from English to Amharic. Then training of data collectors, questionnaire pretesting on $5 \%$ of the sample at Adare Hospital, Hawassa, Ethiopia and continuous supervision during data collection was made. The collected data was checked for completeness and consistency by the group members throughout the data collection period for data quality and completeness.

Data analysis: All the collected data was checked for its completeness and the result was describe by absolute number and percent and also display using tables and charts as necessary, and the data was analyzed after entering into Statistical Package for the Social Sciences (SPSS version 20) for analysis. Significance of the study was obtained at $\mathrm{p}$-value $\leq 0.05$.

\section{Operational definition}

Antenatal care: A care provided to pregnant women before birth.

Common mental disorder: Defined based on the cut off score of the self-reporting questionnaire (SRQ-20) items, participants who scored 6 or more were taken as CMD.

Unplanned pregnancy: Are pregnancies that are mistimed, unintended at the time of conception. Unwanted pregnancy: Are pregnancies that are not accepted, weather it is planned or not.

Prenatal lose: Lose of relatives during pregnancy due trauma etc.
Poor health status:-health status of pregnant women's which manifest with some minor health problems like, (headache), ongoing health concerns like, (DM and HIV) and serious health concerns like, (hypertension).

\section{Ethical consideration}

Ethical clearance was obtained from Ethical review committee of Hawassa University. Official letters was submitted to the Hawassa University referral hospital then the data was collected after taking consent from the study subjects followed a brief discussion and explanation with the women who attend ANC about the purpose and importance of the study. Confidentiality was maintained by omitting their name and personal identification and data was collected only from those who are willing to participate. Participant's involvement in the study was on voluntary basis; participants who are unwilling to participate in the study and those who wish to quite their participation at any stage was informed to do so without any restriction (Tables 1-4).

\section{Results}

\section{Socio-demographic characteristics}

We distributed 237 questionnaires among those the participants and 232 available for analysis giving response rate $97.9 \%$. The mean age of the respondent was 26.6 , the age of the respondent's ranges from 16-43 years. The mean income of the respondents was 3337.86 Ethiopian birr.

\section{Prevalence and associated factors of common mental disorders}

Among the participants (232) of pregnant women, 108(46.6\%) had CMD. As shown in Table 5 the following variables marital status, miscarriage, health status before current pregnancy, community support and baby's father support were statistically associated with antenatal CMD in the bivariate analysis. However, poor health status [some minor problem (headache), ongoing health concern (diabetes mellitus) and serious health concern (hypertension)] before current pregnancy was the associated factors with $\mathrm{CMD}$ among pregnant women who attend ANC in the multivariable analysis. As shown in Table 5 those women who had health problem before their current pregnancy were more likely to have antenatal CMD than those who have no problem at all. Those with some minor health problem (headache) were two times, Ongoing health concern (diabetes mellitus) 2.83 times and Serious health concern (hypertension) 4.17 times more likely to have CMD than those who did not have health problem at all (AOR, 95\% CI 2 (1.06-3.77), (AOR, 95\% CI 2.83 (1.21-6.66) and (AOR, 95\% CI 4.17 (1.24-13.98) respectively.

\section{Discussion}

In the context of previous studies that have shown a high prevalence of CMD in pregnant women in LMICs, the study tried to assess symptoms of CMD among pregnant women who came for ANC follow up. We found that 108 (46.6\%) of pregnant women attending ANC service at Hawassa referral hospital had CMD among participants women of 232 pregnant women, including suicidal ideation, as indicated by a score of six or more on the self-reporting questionnaires (SRQ-20). This estimate falls at the upper margin of the WHO report of CMD (5.2\% to 32.9\%) [15] and also higher than the other study that were done in Adama [17] and St. Paulos Hospital [5] (31.2\% and 26\%) respectively. Also when we compare it with the other study that was done in Butajira, rural part with in the community, it was found to be much higher (12\%) [18]. This can be because of the 
Citation: Abraham Y, Olitaye Z, Alemie T, Tsegaye B, Andualem E (2017) Prevalence of Common Mental Disorders and Factors Associated with These Disorders among Pregnant Women Attend Ante Natal Care Services at Hawassa Referral Hospital, Ethiopia, 2016. J Health Med Informat 8: 280. doi: 10.4172/2157-7420.1000280

Page 4 of 7

\begin{tabular}{|c|c|c|}
\hline Character & Frequency & Percent \\
\hline \multicolumn{3}{|c|}{ Age } \\
\hline $16-20$ & 31 & 13.4 \\
\hline $21-25$ & 74 & 31.9 \\
\hline $26-30$ & 89 & 38.4 \\
\hline $31-35$ & 28 & 12 \\
\hline $36-45$ & 10 & 4.3 \\
\hline \multicolumn{3}{|c|}{ Marital status } \\
\hline Single & 12 & 5.2 \\
\hline Married & 220 & 94.8 \\
\hline \multicolumn{3}{|l|}{ Ethnicity } \\
\hline Sidama & 66 & 28.4 \\
\hline Wolayta & 36 & 15.5 \\
\hline Amhara & 32 & 13.8 \\
\hline Gurage & 24 & 10.3 \\
\hline Oromo & 58 & 25 \\
\hline Other* & 16 & 6.9 \\
\hline \multicolumn{3}{|l|}{ Religions } \\
\hline Orthodox & 65 & 28 \\
\hline Protestant & 121 & 52.2 \\
\hline Muslim & 37 & 15.9 \\
\hline Other** & 9 & 3.9 \\
\hline \multicolumn{3}{|c|}{ Residence } \\
\hline Rural & 17 & 7.3 \\
\hline Urban & 215 & 92.7 \\
\hline \multicolumn{3}{|l|}{ Occupation } \\
\hline Housewife & 103 & 44.4 \\
\hline Employed & 84 & 36.2 \\
\hline Student & 23 & 9.9 \\
\hline Jobless & 13 & 5.6 \\
\hline Other ${ }^{\star \star \star}$ & 9 & 3.9 \\
\hline \multicolumn{3}{|c|}{ Educational status } \\
\hline Unable to read and write & 12 & 5.2 \\
\hline Able to read and write & 32 & 13.8 \\
\hline $1-8$ & 67 & 28.9 \\
\hline $8-12$ & 76 & 32.8 \\
\hline Above diploma & 45 & 19.4 \\
\hline \multicolumn{3}{|c|}{ Duration of relationship } \\
\hline$<5$ year & 103 & 44.4 \\
\hline $5-10$ & 82 & 35.3 \\
\hline$>10$ & 47 & 20.3 \\
\hline \multicolumn{3}{|c|}{ Occupation of husband } \\
\hline Farmer & 10 & 4.3 \\
\hline Merchant & 49 & 21 \\
\hline Employed & 125 & 53.9 \\
\hline Driver & 25 & 10.7 \\
\hline Other ${ }^{\star * \star *}$ & 23 & 9.9 \\
\hline \multicolumn{3}{|c|}{ Monthly income } \\
\hline$<750$ ETB & 14 & 6 \\
\hline 750-1200 ETB & 30 & 12.9 \\
\hline$>1200$ ETB & 188 & 81.1 \\
\hline \multicolumn{3}{|c|}{ Number of children } \\
\hline Males & 56 & 24 \\
\hline Females & 47 & 20.3 \\
\hline Male and Female & 63 & 27.3 \\
\hline
\end{tabular}

*Kabata, Gedio, Tigray; ${ }^{* *}$ Catholic, Waqefene; ${ }^{* * *}$ Merchant, Blue worker; $* * * *$ Guard, Coach

Table 1: Socio-demographic characteristics of pregnant women's attending ANC service at HURH, $2016(n=232)$.

\begin{tabular}{|c|c|c|}
\hline Character & Frequency & Percent \\
\hline \multicolumn{3}{|c|}{ Number of pregnancy } \\
\hline Primgravida & 65 & 28.3 \\
\hline Multigravida & 146 & 62.7 \\
\hline Grand parity & 21 & 9 \\
\hline \multicolumn{3}{|c|}{ History of miscarriage } \\
\hline Yes & 27 & 11.6 \\
\hline No & 205 & 88.4 \\
\hline \multicolumn{3}{|c|}{ History of still birth } \\
\hline Yes & 16 & 6.9 \\
\hline No & 216 & 93.1 \\
\hline \multicolumn{3}{|c|}{ History of abortion } \\
\hline Yes & 17 & 7.3 \\
\hline No & 215 & 92.3 \\
\hline \multicolumn{3}{|c|}{ Presence of adoption } \\
\hline Yes & 12 & 5.2 \\
\hline No & 220 & 94.8 \\
\hline \multicolumn{3}{|c|}{ Stepparent women } \\
\hline Yes & 17 & 7.3 \\
\hline No & 215 & 92.7 \\
\hline \multicolumn{3}{|c|}{ Any medical treatment } \\
\hline No & 195 & 83.7 \\
\hline Evaluation and some advice no & 38 & 16.3 \\
\hline \multicolumn{3}{|c|}{ Intervention } \\
\hline \multicolumn{3}{|c|}{ Current health statues of mother } \\
\hline Good (no problem at all) & 136 & 58.6 \\
\hline Some minor problem & 55 & 23.7 \\
\hline ongoing health concern & 27 & 11.6 \\
\hline Serious health concern & 14 & 6.1 \\
\hline \multicolumn{3}{|c|}{ Status of pregnancy } \\
\hline unplanned \& unwanted & 19 & 8.2 \\
\hline unplanned but wanted & 54 & 23.3 \\
\hline planed & 159 & 68.5 \\
\hline \multicolumn{3}{|c|}{ Gestational age } \\
\hline$<16$ & 48 & 20.7 \\
\hline $20-24$ & 54 & 23.3 \\
\hline $28-32$ & 68 & 29.3 \\
\hline Above 36 & 62 & 26.7 \\
\hline
\end{tabular}

Table 2: Obstetric and clinical characteristics of pregnant women's attending ANC service at HURH, April 1-May15 $(n=232)$.

\begin{tabular}{|c|c|c|c|}
\hline \multicolumn{2}{|c|}{ Character } & Frequency & Percent \\
\hline \multicolumn{2}{|c|}{ Community support } & \\
\hline Yes & 156 & 67.2 \\
\hline No & 76 & 32.8 \\
\hline \multicolumn{2}{|c|}{ Husband support } \\
\hline Yes & 209 & 90.1 \\
\hline No & 23 & 9.9 \\
\hline \multicolumn{2}{|c|}{ Husband feeling } \\
\hline Happy & 213 & 91.8 \\
\hline Unhappy & 19 & 8.2 \\
\hline \multicolumn{2}{|c|}{ Partner violence } \\
\hline Yes & 88 & 37.9 \\
\hline No & 144 & 62.1 \\
\hline \multicolumn{2}{|c|}{ Family debt/conflict } \\
\hline Yes & 97 & 41.8 \\
\hline No & 135 & 58.2 \\
\hline
\end{tabular}

Table 3: Psychosocial history of pregnant women's attending ANC services at HURH, $2016(n=232)$. 
Citation: Abraham Y, Olitaye Z, Alemie T, Tsegaye B, Andualem E (2017) Prevalence of Common Mental Disorders and Factors Associated with These Disorders among Pregnant Women Attend Ante Natal Care Services at Hawassa Referral Hospital, Ethiopia, 2016. J Health Med Informat 8: 280. doi: 10.4172/2157-7420.1000280

Page 5 of 7

\begin{tabular}{|c|c|c|c|c|c|c|c|c|}
\hline \multirow{3}{*}{ Variables } & \multicolumn{2}{|c|}{ Before pregnancy } & \multirow[b]{2}{*}{$\%$} & & \multicolumn{2}{|c|}{ After pregnancy } & \multirow[b]{2}{*}{$\%$} & \multirow[b]{3}{*}{ No } \\
\hline & Frequency & & & & Frequency & & & \\
\hline & Yes & No & Yes & No & Yes & No & Yes & \\
\hline Diabetes militias & 4 & 228 & 1.7 & 98.3 & 5 & 227 & 2.2 & 37.8 \\
\hline Vaginal bleeding & 4 & 228 & 1.7 & 98.3 & 3 & 229 & 1.3 & 98.7 \\
\hline Urinary tract infection & 15 & 227 & 6.5 & 93.5 & 10 & 222 & 4.3 & 95.7 \\
\hline Nausea and vomiting & 6 & 226 & 2.6 & 97.4 & 50 & 182 & 4.6 & 78.4 \\
\hline Hypertension & 7 & 225 & 3 & 97 & 8 & 224 & 3.4 & 96.6 \\
\hline Blood transfusion & 18 & 214 & 7.8 & 92.2 & 0 & 232 & 0 & 100 \\
\hline Accident & 7 & 225 & 3 & 97 & 0 & 232 & 0 & 100 \\
\hline
\end{tabular}

Table 4: History of chronic illnesses and substance use of pregnant women's attending ANC Services at HURH, April 1-May 15 ( $n=232$ ).

\begin{tabular}{|c|c|c|c|c|c|}
\hline \multirow{2}{*}{ Variables } & \multicolumn{2}{|c|}{ CMD } & \multirow{2}{*}{ COR(95.0\% } & \multirow{2}{*}{ AOR $(95 \% \mathrm{Cl})$} & \multirow{2}{*}{ P-value } \\
\hline & Yes & No & & & \\
\hline \multicolumn{6}{|l|}{ Marital status } \\
\hline Single & 3 & 9 & $0.36(0.096-1.38)$ & $2.57(0.65-10.18)$ & 0.18 \\
\hline Married & 105 & 115 & 1 & 1 & - \\
\hline \multicolumn{6}{|l|}{ Miscarriage } \\
\hline Yes & 16 & 11 & $1.78(0.67-3.68)$ & $1.57(0.668-3.68)$ & 0.3 \\
\hline No & 92 & 113 & 1 & 1 & - \\
\hline \multicolumn{6}{|c|}{ Health status before pregnancy } \\
\hline No problem at all & 51 & 85 & 1 & 1 & \\
\hline Some minor problem & 30 & 25 & $1.9(1.01-3.69)$ & $2.0(1.06-3.77)$ & $0.032^{*}$ \\
\hline Ongoing health concern & 17 & 10 & $2.63(1.09-6.3)$ & $2.83(1.21-6.66)$ & $0.017^{*}$ \\
\hline Serious health concern & 10 & 4 & $4.47(1.3-15.3)$ & $4.17(1.24-13.98)$ & $0.02^{*}$ \\
\hline \multicolumn{6}{|l|}{ Community support } \\
\hline Yes & 67 & 89 & 1 & 1 & - \\
\hline No & 41 & 35 & $0.64(0.39-1.29)$ & $0.714(0.39-1.29)$ & 0.266 \\
\hline \multicolumn{6}{|l|}{ Husband support } \\
\hline Yes & 94 & 115 & 1 & 1 & \\
\hline No & 14 & 9 & $0.53(0.2-1.4)$ & $0.48(0.19-1.178)$ & 0.109 \\
\hline
\end{tabular}

*Significant association ( $\mathrm{p}$ 0.05). COR: Crude Odds Ratio; AOR: Adjusted Odds Ratio; Cl: Confidence Interval

Table 5: Factors associated with CMD among pregnant women attending ANC service at HURH, April 1-May 15, 2016 (n=232).

difference in the study area were in the urban part (Hawassa) women are more educated and might be more aware and tend to report more on their CMD symptoms and other factors like, socio-demographic characteristics and socioeconomic factors might be different. But when we compare it with other study that was done in Addis Abeba health center, it was found to be lower than (53.4\%) [19]. The other factor what inhibit direct comparison is the different screening instruments which were used in above mentioned studies except Butajira study and St. Paulos Hospital study which used SRQ-20, other were not validated. When the result of this study is compared with other countries like South Africa, it was found to be comparable (46.7\%) [20] and higher than with Brazilian study (33.6\%).

In the study that was done in Adama hospital marital conflict, previous induced abortion, fear of pregnancy complication, economic problems and unwanted pregnancy were found to be associated significantly with CMD during pregnancy and in other study that was done in Addis Ababa health center, having no formal education, being in elementary school, unplanned pregnancy, support from the baby's father and previous history of depression were associated with CMD during pregnancy. In a study done in rural South Africa, lack of access to a regular income and never having practical support from a partner and family conflict were significantly associated with CMD. In study that was done in Addis Abeba, at the Saint Paul's Hospital ANC clinic among pregnant women in their third trimester attending ANC women with obstetric problems in their current pregnancy, unplanned pregnancy, and psychiatric illness in the past were found to have a strong association with the presence of significant CMD [21]. But in our study pregnant women with previous history of health problem were more likely to be affected or were significantly associated with CMD than those with no health problem before current pregnancy. Those with some minor health problem (headache) were two times, Ongoing health concern(diabetes mellitus) 2.83 times and Serious health concern(hypertension) 4.17 times more likely to have CMD than those who did not have health problem at all (AOR, 95\% CI 2 (1.06-3.77), (AOR, 95\% CI 2.83 (1.21-6.66) and (AOR, 95\% CI 4.17 (1.24-13.98) respectively.

\section{Conclusion and Recommendation}

\section{Conclusion}

In our study among total 232 respondents we have drown the following conclusions.

- The prevalence of CMD among pregnant women who came up for ANC follow up at HURH was higher.

- Pregnant women's with previous history of health problem before current pregnancy was significantly associated with CMD.

- In this study, there was no significant association of CMD with age, religion, ethnicity, marital status, monthly income, obstetric complications and status of pregnancy [22-26]. 
Citation: Abraham Y, Olitaye Z, Alemie T, Tsegaye B, Andualem E (2017) Prevalence of Common Mental Disorders and Factors Associated with These Disorders among Pregnant Women Attend Ante Natal Care Services at Hawassa Referral Hospital, Ethiopia, 2016. J Health Med Informat 8: 280. doi: 10.4172/2157-7420.1000280

Page 6 of 7

\section{Recommendation}

- We recommend to HURH $\mathrm{MCH}$ staff members to give comprehensive interventions are important to reduce the burden of CMD and health care professionals need to enquire about the relevant associated factors especially those pregnant women with previous health problem using such screening instrument and linking to psychiatry unit of pregnant women with high responses of SRQ-20. Such actions will have an enormous public health impact and will contribute to improve the quality of life of the millions of women, their children and even relatives living in low and middle income countries [27-29].

- Further comprehensive studies concerning CMD are critical to understand the extent to which pregnant women are prone to $\mathrm{CMD}$ and to know cause and effect relationship.

\section{Limitations}

This study was a cross-sectional study and thus the cause and effect relationship was difficult to establish. Variables such as smoking cigarettes, drinking alcohol and chewing Khat are less socially acceptable and thus prone to social desirability bias [30-33]

\section{Declarations}

Ethical clearance was obtained from Ethical review committee of Hawassa University. Official letters was submitted to the Hawassa University referral hospital then the data was collected after taking consent from the study subjects followed a brief discussion and explanation with the women who attend ANC about the purpose and importance of the study. Confidentiality was maintained by omitting their name and personal identification and data was collected only from those who are willing to participate. Participant's involvement in the study was on voluntary basis; participants who are unwilling to participate in the study and those who wish to quite their participation at any stage was informed to do so without any restriction [34-38].

\section{Competing Interests}

The authors declare that they have no competing interests.

\section{Authors' Contributions}

YA conceived the study and involved in the study design, reviewed the article, analysis, report writing and drafted the manuscript.

ZO, TA, BT and EA were involved in the study design, analysis and drafted the manuscript. All authors read and approved the final manuscript.

\section{Acknowledgements}

The authors would like to thank the respective study institutions and the study participants for their cooperation in providing all necessary information.

\section{References}

1. Adewuya AO, Ola OB, Aloba OO, Mapayi BM, OKeniyi JA (2008) Impact of postnatal depression on infants' growth in Nigeria. J Affect Disord 108: 191-193.

2. Abiodun OA, Adetoro OO, OgunbodeOO (1993) Psychatric morbidity in a pregnant population in Nigeria. Gen Hosp Psychiatry 15: 125-128.

3. Abiodun OA (2006) Post natal depression in primary care populations in Nigeria. Gen Hosp Psychiatry 28: 133-136.

4. Aderibigbe YA, Gureje O, Omigbodun O (1993) Post natal emotional disorders in Nigerian women. Br J Psychiatry 163: 645-650.

5. Anderson L, Sundstrom-Poromaa I, Xo MB, Wott M, Bondestam K, et al. (2003) Point prevalence of psychiatric disorders during the second trimester of pregnancy; a population based study. Am J Obstet Gynecol 189: 148-154.

6. Antelman G, Kaaya S, Wei R (2007) Depressive symptom increase risk of HIV disease progression and mortality among women in Tanzania. J Acquir Immune Defic Syndr 44: 470-477.
7. Araujo T, Pinhops A, Almeida M (2005) Prevalence of common mental disorders among mothers $v$ infant.

8. Assefa M (2011) Assesment of prevalence of antenatal depression disorder andassociated factors among adama hospital anc clinic, adama Ethiopia. Pub Healt 25: 23-27.

9. Bekele D, Asmeret A (2013) Screening for antenatal depression: a formative study for development of a perinatal mental health liaison service.

10. Beusenberg M, Orley J (1994) A user's guide to the self-reporting questionnaire (SRQ). Geneva division of mental health.

11. Biratu A (2015) Prevalence of antenatal depression and associated factors among pregnant women attending ANC clinic at public health centers in Addis Abeba, Ethiopia. Reprod Health 12: 99.

12. Bonari L, Pinto N (2004) Perinatal risk of untreated depression during pregnancy. Can J Psychiatry 49: 726-735

13. Bussel JV, Spitz B, Demyttenaere K (2006) Women's mental health before during and after pregnancy; a population-based controlled cohort study. Birth 33: $297-302$

14. Carey U, Mitchell M, Mark L (2002) Social capital and mental distress in an impoverished community city and community199-222 pub Med/Google scholar. CRC 1: 1-25.

15. Goldberg D, Huxley P (1992) Common mental disorders; a bio-social model. Willey 25: 1-194

16. Faisal-cury A, Meneze P, Araya R, Zugaib M (2009) Common mental disorder during pregnancy: prevalence and associated factors among low income women in sao Paulo, brazil, are women mental health. Arch Womens Ment Health 12: 335-343.

17. Fisher J, Meena C (2012) Prevalence and determinants of common menta disorders in women low and lower middle income countries. Bull World Health Organ 90: 139-149.

18. Ethiopian Demographic and Health Survey (2011) Addis abeba, Ethiopia and Calverton, Central Stastical Agency and ICF International, Maryland, USA

19. Gausia K, Fisher C, Alim O (2009) Antenata depression and suicidal ideation among rural Bangladeshi women: a community based study. Arch Women Ment Health 12: 351-358.

20. Gelder M, Gath D, Mayou R (1989) Oxford textbook of psychiatry

21. Hanlon C, Medhin G, Alem A, Tsefaye F, Lakew Z, et al. (2010) Impact of antenatal common mental disorders upon prenatal outcomes in Ethiopia. Trop Med Int Health 14: 156-166.

22. Heron J, O'conor T, Evans J, Golding J, Glove V (2004) The course of anxiety and depression through pregnancy and the postpartum in community sample affect disorder. J Affect Disord 80: 65-73.

23. Giang KV, Tv DZ, Kullgren G, Allebeck P (2010) Prevalence of mental distress and use of health services in a rural district in Vietnam, glob health action. Glob Health Action 3: 2025.

24. Kirkwood B, Patel V, Araya R, Chowdhary N (2008) Detecting common menta disorders in primary care in India: a comparison of five screening questionnaires psycho. Med Psychol Med 38: 221-228.

25. Moss N, Karmaliani R, Asad N, Bann C, Mcclure E (2009) Prevalence of anxiety depression and associated factors among pregnant women of Hyderabad, Pakistan. Int J Soc Psychiatry 55: 414-424.

26. Murray J, Lopez A (1996) The global burden of disease; a comprehensive assessment of mortality disability from disease, injuries and risk factors. Boston: Harvard School of Public Health.

27. Nasreen $\mathrm{H}$ (2010) Low birth weight in offspring of women with depressive and anxiety symptoms during pregnancy: results from a population based study in Bangladesh. BMC Public Health 10: 515.

28. Patel V (2006) Maternal psychological morbidity and low birth weight in India. Br J Psychiatry 188: 284-285.

29. Pereira P, Lovisi G (2008) Prevalencia da depression gestational associated factors.

30. Rahman A (2007) Association between antenatal depression and low birth weight. Acta Psychiatr Scand 115: 481-486. 
Citation: Abraham Y, Olitaye Z, Alemie T, Tsegaye B, Andualem E (2017) Prevalence of Common Mental Disorders and Factors Associated with These Disorders among Pregnant Women Attend Ante Natal Care Services at Hawassa Referral Hospital, Ethiopia, 2016. J Health Med Informat 8: 280. doi: 10.4172/2157-7420.1000280

Page 7 of 7

31. Rahman A, Lqbal Z, Harrington R (2003) Life events, social support and depression in child birth: perspectives from a rural community in the developing world. Psychol Med 33: 1161-1167.

32. Ross J, Hanlon C, Medhin G, Alem A, Tesfaye F, et al. (2011) Perinatal mental distress and infant morbidity in Ethiopia; cohort. Arch Dis Child Fetal Neonatal 96: 59-64.

33. Sadock B, Sadock V (2007) Synopsis of psychiatry, Philadelphia Lippincott Williams and Wilkins.

34. Tamsen R (2011) Depression among pregnant women testing for HIV in rura South Africa.
35. Van Bussel JC, Spitz B, Demyttenaere K (2008) Women's mental health before, during, and after pregnancy: apopulation-based controlled cohort study. Birth 33: 297-302.

36. Vans E, Heron J, Francomb H, Oke S, Golding J (2001) Cohort study of depressed mood during pregnancy and after child birth. BMJ 323: 257-260.

37. Worku B, Servili C, Medhin G, Hanlon C, Tomlinson M (2010) Materna common mental disorders and infant development in Ethiopia. BMC Public Health 10: 693.

38. World Health Organization (WHO) (1994) Auser's guide to the self-reporting questionnaire (SRQ). Geneva 94: 1-90. 